\title{
Evaluation of crack growth rate and growth model of ultrafine grained copper
}

\author{
M. Goto ${ }^{1}$, S. Z. $\operatorname{Han}^{2}$, K. Euh ${ }^{2}$, J.-H. Kang ${ }^{2}$, K. Kamil ${ }^{1}$, \\ N. Kawagoishi ${ }^{3} \&$ S. S. Kim ${ }^{4}$ \\ ${ }^{I}$ Department of Mechanical Engineering, Oita University, Japan \\ ${ }^{2}$ Korea Institute of Materials Science, Republic of Korea \\ ${ }^{3}$ Department of Mechanical Engineering, Kagoshima University, Japan \\ ${ }^{4}$ Engineering Research Institute, \\ Gyeongsang National University, Republic of Korea
}

\begin{abstract}
High-cycle fatigue tests were carried out on smooth specimens of ultrafine grained (UFG) copper produced by equal channel angular pressing for 12 passes. The growth behavior of a small surface-crack was monitored. A major crack, which led to the final fracture of the specimen, initiated from shear bands (SBs) at an early stage of stressing. Different tendencies of growth behavior occurred depending on the ranges of crack length. To understand the changes in growth rate and fracture surface morphologies, a quantitative model describing a crack growth mechanism were developed considering the reversible plastic zone size at a crack tip. In addition, the crack growth rate of UFG copper was evaluated by applying the small-crack growth raw.
\end{abstract}

Keywords: fatigue, surface damage, fine grains, copper, crack propagation.

\section{Introduction}

Ultrafine grained (UFG) materials processed by equal channel angular pressing (ECAP) have many unique properties due to the unusual characteristics of the microstructure with non-equilibrium states. Regarding the fatigue of UFG materials, most studies have concentrated on cyclic deformation, fatigue life, surface damage formation and underlying microstructural mechanisms [1-6]. Since the fatigue life of machine components and structures are mainly controlled by the growth life of a fatigue crack, the crack growth behavior should 
be clarified for the design of safe machine components and structures. Recently, the growth behaviors of millimeter-range cracks in UFG metals were studied for compact-tension $[5,7,8]$ and single edge-notched specimens $[9,10]$. On the other hand, the fatigue life of smooth specimens is approximately controlled by the growth life of a small surface crack [11]. This means that the growth behavior of small cracks must be clarified to estimate the fatigue life of plain members. However, little has been reported on the growth behavior of small surface cracks in UFG metals.

In this study, stress-controlled fatigue tests were conducted on UFG copper. The formation of surface damage and growth behavior of a surface crack were monitored to clarify the physical background of fatigue damage. In addition, fracture surface analysis was conducted by scanning electron microscopy (SEM). The growth model of a small surface-crack was discussed by considering its growth path on the specimen surface and the results of fracture surface analysis.

\section{Experimental procedures}

The material used was pure oxygen-free copper (OFC, $99.99 \mathrm{wt} \% \mathrm{Cu}$ ). Prior to performing the ECAP process, the materials were annealed at $500{ }^{\circ} \mathrm{C}$ for $1 \mathrm{hr}$ (average grain size: $100 \mu \mathrm{m}$ ). An ECAP die used had an angle of $90^{\circ}$ between intersecting channels. The angles at the inner and outer corners of the channel intersection were 90 and $45^{\circ}$, respectively. Repetitive ECAP was accomplished according to the Bc-route. 12 passages of extrusion resulted in an equivalent shear strain of about 11.7, respectively. The mechanical properties before ECAP were $232 \mathrm{MPa}$ tensile strength, 65\% elongation and a Vickers hardness number of 63. After 12 passages of ECAP the properties changed to $402 \mathrm{MPa}, 32 \%$, and 131 , respectively. The coarse grained copper and UFG copper processed through 12 passes are referred to hereafter as CG and UFG, respectively.

Round bar specimens of $5 \mathrm{~mm}$ diameter were machined from the respective processed bars. The fatigue specimens were electrolytically polished $(\approx 25 \mu \mathrm{m}$ from the surface layer) prior to mechanical testing in order to remove any preparation affected surface layer.

All fatigue tests were carried out at room temperature using a rotating bending fatigue machine operating at $50 \mathrm{~Hz}$. The observations of fatigue damage on the specimen surface were performed using both optical microscopy (OM) and SEM. The fracture surface analysis was performed by SEM. The crack length, $l$, is a length measured along the circumferential direction of the surface. The stress value referred to is that of the nominal stress amplitude, $\sigma_{a}$, at the minimum cross section ( $5 \mathrm{~mm}$ diameter).

For EBSD-analyses, the cross section perpendicular to press direction was observed. EBSD mappings were carried out using a Tescan Mira II SEM incorporating an EDAX-TSL Hikari EBSD detector. Each pixel was $40 \mathrm{~nm}$ for UFG samples and $1.0 \mu \mathrm{m}$ for coarse grain samples and hexagonal in shape. Transverse cross sections of as-ECAPed and post-fatigued bars were cut to prepare specimens for transmission electron microscopic (TEM) observation. Specimens were mechanically polished to a thickness of $100 \mu \mathrm{m}$, and then 
subject to twin-jet electropolishing using a solution comprising $200 \mathrm{ml} \mathrm{CH}_{3} \mathrm{OH}$ and $100 \mathrm{ml} \mathrm{HNO}_{3}$. The jet thinning was conducted at $-30{ }^{\circ} \mathrm{C}$. Microstructure and diffraction patterns were analyzed using JEOL JME-2100F at $200 \mathrm{kV}$.

\section{Experimental results and discussion}

\subsection{Microstructure}

Fig. 1(a) shows inverse pole figure (IPF) maps and grain boundary (GB) maps of UFG copper. The cross section perpendicular to pressing direction was observed in each sample. The GBs in GB maps are denoted either by red lines corresponding to low angle GBs where the misorientation, $\theta$, is between $2^{\circ}$ and $15^{\circ}$ or by black lines corresponding to high angle GBs with $\theta>15^{\circ}$. The microstructure retains large fraction of equiaxed grains with high angle GBs. The average grain/cell size was measured as $295 \mathrm{~nm}$.

The characteristics of GBs plotted as a function of the misorientation angle is shown in Fig. 1(b). The solid curve in each plot represents the misorientation profile of random orientations as calculated by Mackenzie and Thomson. Fig. 1(b) shows that the distribution of misorientation angles has a weak bimodal character with peaks at low and high misorientation angles. The fraction of high angle GBs is about $65 \%$. Although there remains an excess of low angle GBs which in inconsistent with the prediction because of the continuous introduction of dislocations in each passage of ECAP processing, the misorientation distribution appears to be nearly similar to the random orientation distribution.

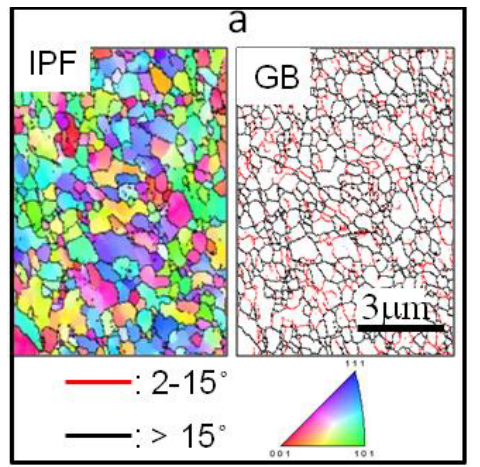

Figure 1: (a) OIM orientation and GB maps; (b) Histograms of the misorientation angles; A random distribution is indicated by solid lines superimposed on the histograms.

\subsection{Fatigue characteristics and surface damage under cyclic stressing}

Significant cyclic softening of UFG copper has been reported by many investigators [1, 12-14]. Agnew and Weertman [1] studied the softening property by means of hardness measurements of post-fatigued specimens. They 
showed that UFG copper prepared by severe plastic deformation is susceptible to cyclic softening, where softening is found to decrease at lower strain amplitudes. In their studies, the measurements of hardness were performed on cross sections of the post-fatigued specimens. Since fatigue cracks are usually initiated at the sample surface, the surface hardness should be measured for understanding fatigue damage of UFG materials. Fig. 2 shows the change in surface Vickers hardness (load: $2.9 \mathrm{~N}$ ) during repeated stressing of $\sigma_{a}=120 \mathrm{MPa}$. Inserted OM micrographs show a change in surface damage within the same observed area monitored at initial, medium and final stages of cycling. Here, each plot represents an average of the hardness measurements taken at six different locations. The maximum errors of the raw average hardness measurements were roughly within $\pm 10 \%$. Surface hardness decreases gradually with cycling in initial stages, followed by a significant drop in hardness. By investigating the change in surface hardness and formation process of surface damage together, it is found that this considerably large drop in hardness in the latter half of the fatigue life is closely related to the significant formation of damaged areas.

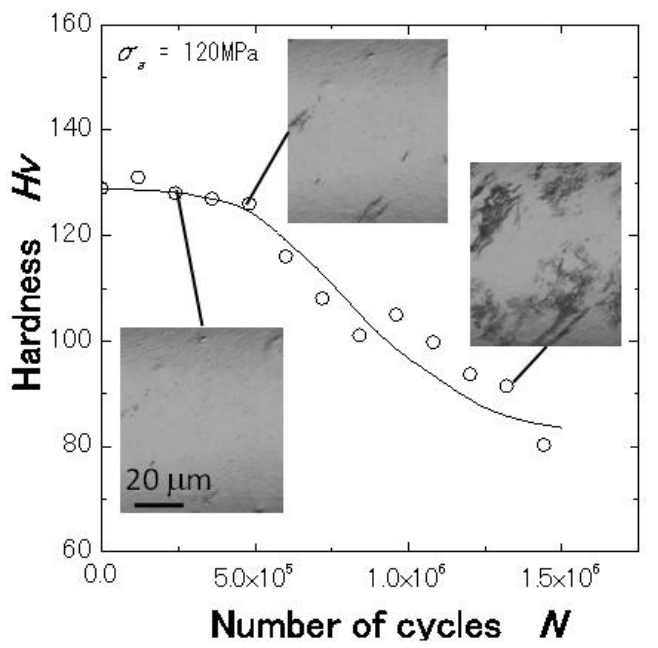

Figure 2: $\quad$ Change in surface hardness during stressing of $\sigma_{a}=120 \mathrm{MPa}$.

Regarding the UFG copper processed by ECAP, most studies [1, 12-14] on low-cycle fatigue indicated that the hardness measured on cross sections of postfatigued specimens is considerably dropped but its drop is found to decrease at lower strain amplitudes. Even in the present specimens fatigued under lower stress amplitudes, the surface hardness exhibited a dramatically large drop. The hardness drop was closely related to the formation behavior of surface damage: the formation of surface damage was accelerated in the latter half of fatigue life, resulting in a significant hardness drop, whereas the mild damage formation in an initial stage of cycling brought a moderate hardness drop. It should be concluded that, thus, the initial (moderate) drop in hardness appears to result mainly from a decrease in the dislocation density inside the grains/GB-regions 
and the formation of SBs. Regarding the dislocation density after fatigue, $\mathrm{Xu}$ et al. [15] conducted strain-controlled fatigue tests of commercial copper $(99.8 \%$ $\mathrm{Cu}$ ) processed by ECAP for 6 passes through C-route (after each pressing, the billet bar was rotated around its longitudinal axis through $180^{\circ}$ ). From TEM observations and EBSD grain maps, they indicated that post-fatigued structures have narrower GBs and lower dislocation density in grain interiors when compared to those in virgin microstructures. For stress-controlled fatigue tests under low plastic strain amplitude (less than $5 \times 10^{-4}$ ), Kunz et al. [12] indicated the formation of narrower GBs and lower dislocation densities in the grain interior for post-fatigued specimens of UFG copper $(99.9 \% \mathrm{Cu})$.

In the latter half of the fatigue life, on the other hand, the surface hardness exhibits a significant drop tendency with a large, simultaneous extension of damaged regions (Fig. 2). As the microstructural background of hardness drop (softening) of copper processed by ECAP, the coarsening of ultrafine grains has been discussed. Höppel et al. [3] showed that pronounced grain coarsening is related to a marked cyclic softening in strain-controlled fatigue tests. Thermally activated grain coarsening must be considered as one other main reason for the
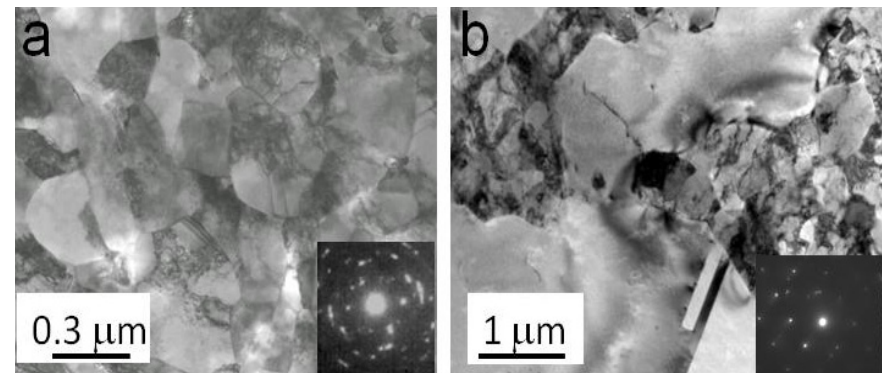

Figure 3: $\quad$ TEM micrographs: (a) pre-fatigue, (b) post-fatigue $\left(\sigma_{a}=100 \mathrm{MPa}\right.$, $\left.N_{f}=3.1 \times 10^{6}\right)$.

cyclic softening $[16,17]$. Fig. 3 shows the TEM micrographs of as-ECAPed and post-fatigued samples. In spite of very low applied stress amplitude $\left(\sigma_{a}=100\right.$ MPa: about $25 \%$ of tensile strength) under stress controlled fatigue, coarsened grains embedded within the original fine grain/cell regions are generated after $3.1 \times 10^{6}$ repetitions. Evidently, purity and fatigue time might be important in determining the coarsening of microstructure.TEM micrograph of post fatigued specimen indicated grain coarsening and decrease in dislocation density inside coarsened grains. A cyclic softening in the latter half of the fatigue life results from the decreased dislocation density, shear banding and cell/grain-coarsening. The primary factor of significant hardness drop appears to be the grain coarsening. It has been suggested that the plastic strain localization during cyclic deformation induces the dynamic grain growth and causes the development of SBs [18]. The heavily extended surface damage in later fatigue stages indicates the formation of coarse grains, leading to the significant drop in surface hardness. 


\subsection{Crack growth behavior}

Fig. 4 shows an initial growth behavior of a major crack. After the initiation of a crack, the crack tended to grow along the shear direction of the final pressing. When the crack length reached specific crack length $\left(l=0.1-0.2 \mathrm{~mm}\right.$ at $\sigma_{a}=$ $100 \mathrm{MPa}$ ), however, the change in crack growth direction occurred.

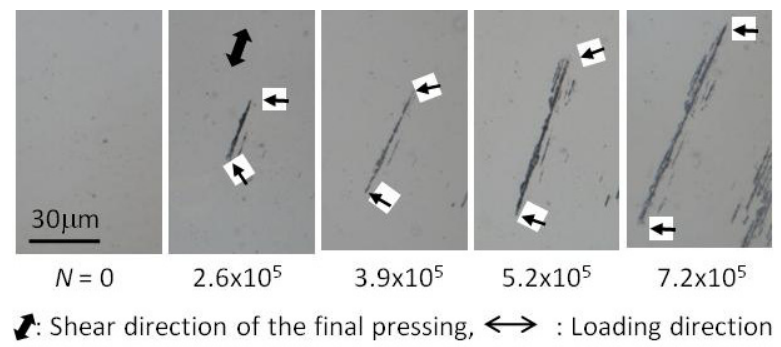

Figure 4: Changes in the surface state during stressing $\left(\sigma_{a}=100 \mathrm{MPa}\right)$.

Fig. 5(a) shows the growth curve ( $\ln l$ vs. $N$ ) of major cracks. Like conventional grain-sized materials, the crack growth life from an initial size (e.g. $20 \mu \mathrm{m}$ ) to fracture accounts for about $60-90 \%$ of the fatigue life of the specimens. The growth curves at higher stress amplitudes tend to approximated by straight lines, whereas the crack growth curves at $\sigma_{a}=100$ and $120 \mathrm{MPa}$ are roughly divided into three stages. In the first stage the crack length increases sharply with stressing and this was followed by a change in the slope of the growth curve. In the second stage the actual crack length after the slope change is smaller than the length expected from an extension of the crack growth curve from the first stage.
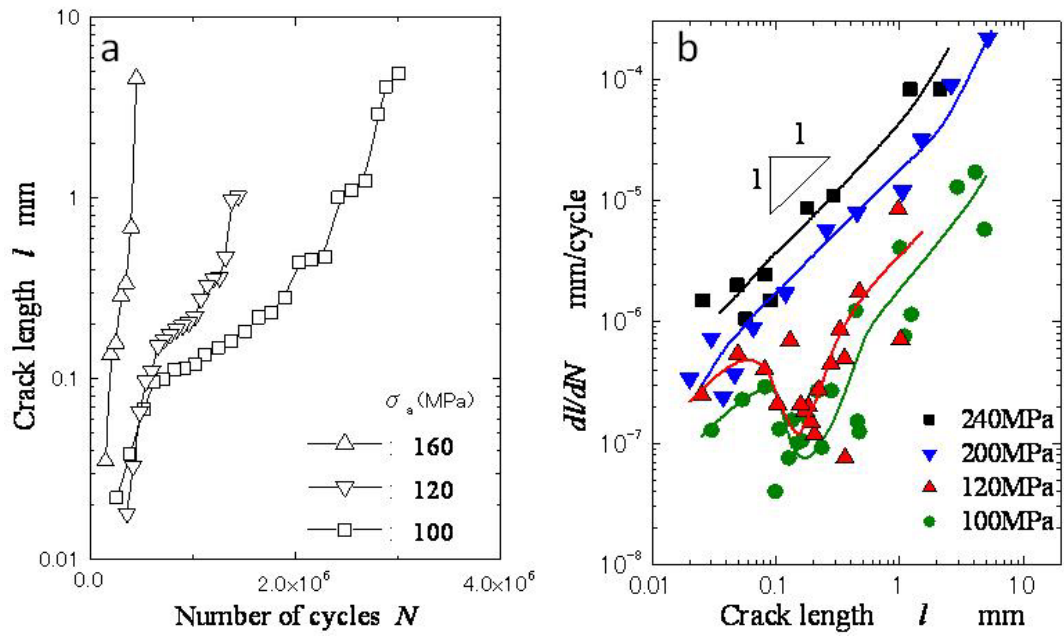

Figure 5: $\quad$ (a) Crack growth curve; (b) $d l / d N$ versus $l$ relation. 
To study qualitatively the growth behavior of both UFG copper, a CGR $(d l / d N)$ was calculated based on raw growth data. Fig. 5(b) shows $d l / d N$ vs. $l$ indicating a lower CGR. This retarded growth ceased before the crack length reached about $l=0.3$ to $0.5 \mathrm{~mm}$ depending on the applied stress amplitude. In tertiary stage the growth curve becomes steeper and is approximated by linear relation. The linear relation nearly holds at high stress amplitudes, however the relations at low stress amplitudes exhibit a significant fluctuation, namely the CGR tends to increase initially with an increasing crack length. When the CGR reached at around $d l / d N=3 \times 10^{-7} \mathrm{~mm} / \mathrm{c}$, however, a temporary drop of CGR occurs. The CGR after temporary drop gradually increases with further cycling. Once the CGR exceeds $d l / d N=10^{-6} \mathrm{~mm} / \mathrm{c}$, the CGR linearly increased with an increase in crack length, holding the relation that CGR is nearly proportional to crack length.

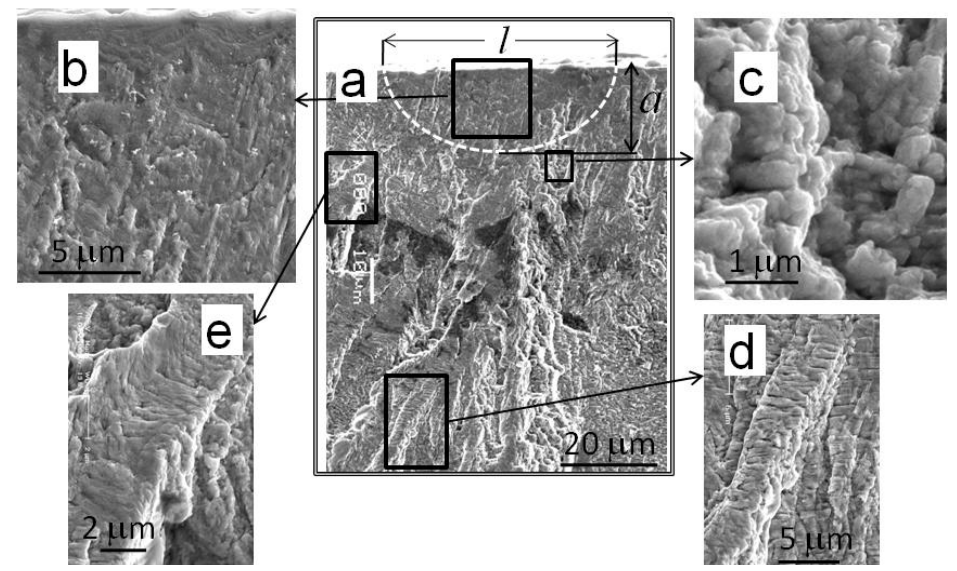

Figure 6: $\quad$ SEM micrographs of the fractured surface formed at $\sigma_{a}=100 \mathrm{MPa}$ : (a) macroscopic view beneath the crack initiation site, (b) planar surface formed at about $5 \mu \mathrm{m}$ beneath the surface, (c) granulated surface formed at about 22 and $45 \mu \mathrm{m}$ beneath the surface, respectively, (d) striation formed below $80 \mu \mathrm{m}$ beneath the surface, and (e) a striated plateau surrounded with granulated surfaces.

To clarify the reason for transient retarded crack growth, SEM analysis of fracture surface were carried out. Fig. 6 shows the post-fatigued fracture surface at $\sigma_{a}=100 \mathrm{MPa}$. Fig. 6a shows a whole macroscopic view of the crack initiation site. Fig. $6 \mathrm{~b}$ shows a magnified view of the fracture surface, a few micrometers beneath the surface ( $a=5 \mu \mathrm{m}, a$ : crack depth). A flat fracture surface is observed. With further crack propagation the morphological features of the fracture surface changed as a granulated surface is observed at $22 \mu \mathrm{m}$ beneath the crack initiation site (Fig. 6c). Interestingly, the grain size on the granulated fracture surface is roughly equivalent to the grain size of the material (Fig. 6c). At about $80 \mu \mathrm{m}$ below the surface, striation features that are nearly perpendicular 
to the macroscopic growth direction are recognized (Fig. 6d). In addition, a striated plateau (Fig. 6e) surrounded with granulated surface is observed at equivalent crack depth where granulated surfaces are formed.

\subsection{Crack growth model and evaluation of crack growth rate}

Fatigue cracks usually propagate as a result of the accumulation of irreversible plastic deformation at a crack tip. In addition, the formation of a plastically deformed zone is closely related to microstructural inhomogeneity of materials. To study the crack growth mechanism a relation between the reversible plastic zone (RPZ) size at the crack tip and microstructural factors such as grain (cell) sizes, slip orientation, etc., should be investigated. The crack growth mechanism is thus discussed paying particular attention to the interrelationship between the RPZ size at the crack tip and the grain (cell) size of the material.

Here, the reversible plastic zone size, $r_{r p}$, under a plane strain condition was defined as:

$$
r_{r p}=\frac{1}{2 \sqrt{2} \pi}\left(\frac{\Delta K_{e f f}}{2 \sigma_{0.2 c}}\right)^{2}
$$

where $\Delta K_{\text {eff }}$ is the effective stress intensity factor range and $\sigma_{0.2 c}$ is the cyclic $0.2 \%$ proof stress. $\Delta K_{\text {eff }}$ was calculated from the relation $\Delta K_{\text {eff }}=U \Delta K$. $U$ and $\Delta K$ are the crack opening ratio and the stress intensity factor range, respectively. Jono et al. [19] conducted plane-bending fatigue test (with a stress ratio, $R=-1$ ) of smooth specimens, for structural steels. They measured the opening-closing behavior of small surface-cracks by using the unloading elastic compliance method. The measurements showed that $U$-values of crack depths under $0.1 \mathrm{~mm}$ are between 0.8 to 0.6 . In the present calculations, $U=0.7$ was used. The solution for $\Delta K$ was taken from Fonte and Freitas for semi-elliptical surface cracks in round bars under bending [20]. Calculated values of $r_{r p}$ and ratios of the grain size of the material, $r_{r p} / d$, are shown in Table 1 for the three crack depths. Essentially, different fracture surfaces were observed (Fig. 6). Consequently, planer, granular and striated fracture surfaces were formed under a range of $r_{r p}$ $/ d<1, r_{r p} / d \doteqdot 1-2$ and $r_{r p} / d>2$, respectively.

Table 1: $\quad$ Values of reversible plastic zone sizes and their ratio to the grain size.

\begin{tabular}{|c|c|c|c|c|c|c|}
\hline $\begin{array}{c}\text { Sample } \\
\text { (Value of } d \text { ) }\end{array}$ & $\begin{array}{r}\sigma_{a} \\
\mathrm{MPa}\end{array}$ & $\begin{array}{c}l \\
\mu \mathrm{m}\end{array}$ & $\begin{array}{c}a \\
\mu \mathrm{m}\end{array}$ & $\begin{array}{l}r_{r p} \\
\mathrm{~nm}\end{array}$ & $r_{r p} / d$ & $\begin{array}{l}\text { Fracture } \\
\text { surface* }\end{array}$ \\
\hline & & 15 & 4.8 & 52 & 0.18 & Fig. $6 \mathrm{~b}$ \\
\hline UFG12 & 100 & 100 & 32 & 348 & 1.18 & Fig. $6 c$ \\
\hline$(d=295 \mathrm{~nm})$ & & 250 & 80 & 863 & 2.93 & Fig. 6d \\
\hline
\end{tabular}

*: Corresponding micrographs in Fig. 6. 
Figure 7 schematically illustrates the interrelationship between the RPZ and grains in the vicinity of the crack tip. When the RPZ size is smaller than the grain size (Fig. 7a), a crack appears to grow by a mechanism that conforms to the individual deformation mode of the localized area inside the grain and adjacent to grain boundaries (GBs). Segal [21] has shown oriented distributions of defects along the shearing plane of the pressing in a material processed by ECAP. Here, the defects refer to dislocations, grain boundaries and cellular substructure. This means that diffusion is accelerated considerably in regions along the shear direction of the final pressing, where GB sliding (GBS) can occur easily [22-24]. Thus the crack may propagate with the assistance of sliding along the maximum shear stress direction showing a planar fracture surface and a straight growth
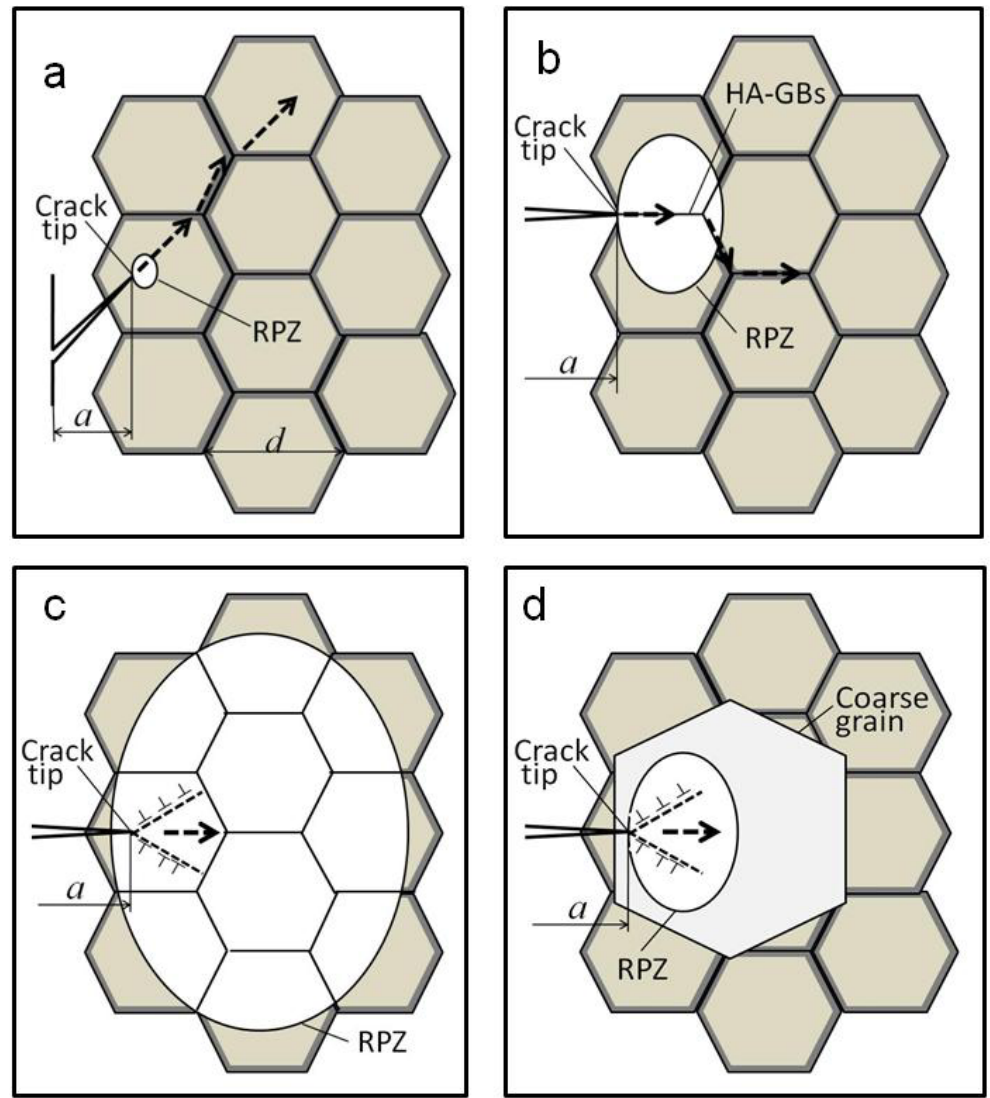

Non-equilibrium state

: Higher non-equilibrium state

Figure 7: Schematic illustration of the crack growth mechanism in UFG12: (a) $r_{r p} / d<1$ : planar surface formation, (b) $r_{r p} / d \approx 1$ : granular surface formation, (c) $r_{r p} / d>>1$ : striation formation, and (d) striated plateau formation within coarsened grains. 
path along the shear direction of the final pressing. When the RPZ is 1 to 2 times the grain size (Fig. 7b) the crack should grow along GBs where an incompatibility of deformation in adjacent grains is concentrated, showing an intergranular crack growth path and a granulated fracture surface. Such a growth path may be convenient for roughness-induced crack closure which contributes to a decrease in CGR. When the RPZ size is more than 3 to 4 times the grain size size (Fig. 7c) the crack propagates because of the striations formation mechanism which is associated with crack tip retardation and blunting [25]. In addition to above stated mechanisms, for coarse grains which are evolved during cyclic stressing and are larger than a few times RPZ size, the crack grows with the formation of striated surface inside the grains as a result of irreversible plastic deformation at the crack tip, showing striated plateaus (Fig. 7e). It can thus be concluded that a temporary decrease in CGR, results from a change in the crack growth mechanism associated with the interrelationship between RPZ size and grain sizes.

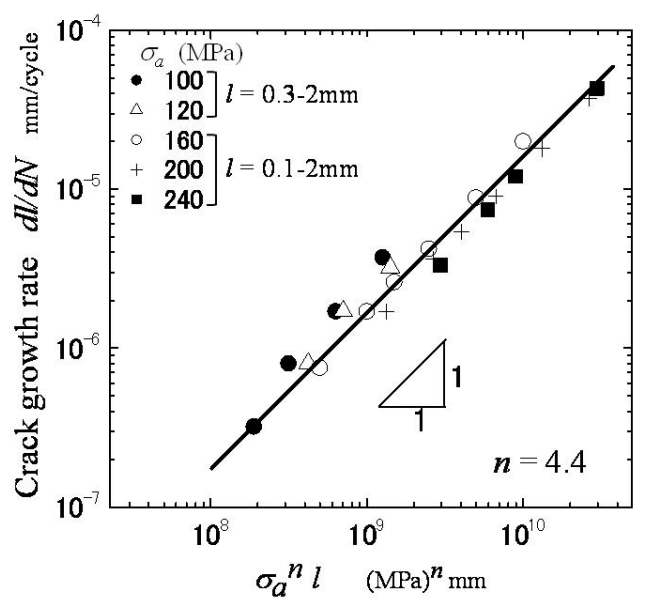

Figure 8: $\quad$ Growth data of small cracks: $d l / d N$ vs. $\sigma_{a}{ }^{n} l$ relation $(n=4.4)$.

It has been shown that the growth rate of small cracks cannot be treated by stress intensity factor range $\Delta K$. In such a case, the CGR of small crack is determined uniquely by a term $\sigma_{a}{ }^{n} l$, which is derived from an assumption that the CGR is proportional to RPZ size [11]. Fig. 8 shows the growth data of a mechanically small crack; $d l / d N$ vs. $\sigma_{a}{ }^{n} l$ relation. The value of $n$ is material constant and was 4.4. All growth data plotted based on $\sigma_{a}{ }^{n} l$ are on a straight line. The CGR of small cracks growing by striation formation mechanism is estimated by the term $\sigma_{a}{ }^{n} l$.

\section{Conclusions}

The main findings of this study can be summarized as follows: 
(1) The surface damage of UFG coppers was gradually formed with cycling, but significant extension of damaged areas was occurred in the latter half of fatigue life. Correspondingly, surface hardness exhibited an initial mild dropping term and subsequent severe drop in the latter half of fatigue life. The initial hardness drop strongly depends on the absorption of mobile dislocations at non-equilibrium GBs. The subsequent severe drop may be attributed to the grain coarsening.

(2) The CGR temporarily dropped at around $d l / d N=3 \times 10^{-7} \mathrm{~mm} / \mathrm{c}$, and then was gradually recovered with subsequent cycling.

(3) The fracture surface showed a planar, granular and striated surface as the crack continued to grow. The ratio of the RPZ size at the crack tip to the grain size, $r_{r p} d$, was calculated for crack lengths where a planar, granular and striated surface was observed. The values of $r_{r p} d$ for crack lengths of the planer, granular and striated fracture surfaces corresponded to a range of $r_{r p} d<1, r_{r p} d$ between 1 and 2 , and $r_{r p} d>3$, respectively.

(4) To understand the change in fracture surface morphologies, a quantitative model describing the crack growth mechanism was developed based on the RPZ size and microstructural factors. The changes in the CGR and morphological features of the fracture surface were successfully explained by this model.

(5) The CGR of a mechanically small surface crack could not be estimated by the stress intensity factor range, but it was uniquely determined by a term, $\sigma_{a}{ }^{n} l$, which is derived from an assumption that CGR is proportional to RPZ size. The $n$ is material constant and was 4.4 .

\section{Acknowledgements}

This study was supported by a Grant-in-Aid (20560080) for Scientific Research (C) from the Ministry of Education, Science, and Culture of Japan, and a grant from the Fundamental R\&D Program for Core Technology of Materials funded by the Ministry of Commerce, Industry and Energy, Republic of Korea.

\section{References}

[1] Agnew, S.R.\& Weertman, J.R., Materials Science and Engineering, A 244, pp. 145-153, 1998.

[2] Vinogradov, A. \& Hashimoto, S., Materials Transactions, 42, pp. 74-84, 2001.

[3] Höppel, H.W., Zhou, Z.M., Mughrabi, H. \& Valiev, R.Z., Philosophical Magazine, A 87, pp. 1781-1794, 2002.

[4] Mughrabi, H., Höppel, H.W. \& Kautz, M., Scripta Materialia, 51, pp. $807-$ 812, 2004.

[5] Vinogradov, A., Nagasaki, S., Patlan, V., Kitagawa, K. \& Kawazoe, M., NanoStructure Materials, 11, pp. 925-934, 1999.

[6] Goto, M., Han, S.Z., Yakushiji, T., Lim, C.Y. \& Kim, S.S., Scripta Materialia, 54, pp. 2101-2106, 2006. 
[7] Pao, P.S., Jones, H.N., Cheng, S.F. \& Feng, C.R., International Journal of Fatigue, 27, pp. 1164-1169, 2005.

[8] Chung, C.S., Kim, J.K., Kim, H.K., \& Kim, W.J., Materials Science and Engineering, A337 (2002) pp. 39-44, 2002.

[9] Kim, H.K., Choi, M-I., Chung, C.S. \& Shin, D.H., Materials Science and Engineering, A340, pp. 243-250, 2002.

[10] Hanlon, T., Tabachnikova, E.D. \& Suresh, S., International Journal of Fatigue, 27, pp. 1147-1158, 2005.

[11] Nisitani, H., Goto, M. \& Kawagoishi, N., Engineering Fracture Mechanics, 41, pp. 499-513, 1992.

[12] Kunz, L., Lukáš, P. \& Svoboda, M., Materials Science and Engineering, A424, pp. 97-104, 2006.

[13] Maier, H.J., Gabor, P. \& Karaman, I., Materials Science and Engineering, A410-11, pp. 457-461, 2005.

[14] Agnew, S.R., Vinogradov, A., Hashimoto, S. \& Weetman, J.R., Journal of Electronic Materials, 28, pp. 1038-1044, 1999.

[15] Xu, C., Wang, Q., Zheng, M., Li, J., Huang, M., Jia, Q., Zhu, J., Kunz, L. \& Buksa, M., Fatigue behavior and damage characteristic of ultra-fine grain low-purity copper processed by equal-channel angular pressing (ECAP), Materials Science and Engineering, A475: 249-256, 2008.

[16] Mughrabi, H. \& Höppel, H.W., Cyclic deformation and fatigue properties of very fine-grained metals and alloys, International Journal of fatigue, 32, pp. 1413-1427, 2010.

[17] Molodova X, Gottstein G, Winning M, Hellmig RJ., Thermal stability of ECAP processed pure copper, Materials Science and Engineering, A460461, pp. 204-213, 2007.

[18] Furukawa, Y., Fujii, T., Onaka, S. \& Kato, M., Materials Transactions, 50, pp. 70-75, 2009.

[19] Jono, M., Song, J., Yama, Y., Nisigaichi, N., Okabe, M. \& Kikukawa, M., Transactions of Japan Society of Mechanical Engineers, Ser-A, 51, pp. 1677-1686, 1985.

[20] Fonte, M da. \& Freitas, M de., International Journal of Fatigue, 21, pp. 457-463, 1999.

[21] Segal, V.M., Materials Science and Engineering, A197, pp. 157-164, 1995.

[22] Valiev, R.Z., Kozlov, E.V., Ivanov, Yu F. Lian, J., Nazarov, A.A. \& Baudelet, B., Acta Metallurgical Materials, 42, pp 2467-2475, 1994.

[23] Chinh, N.Q., Szommer, P., Horita, Z. \& Langdon, T.G., Advanced Materials, 18, pp. 34-39, 2006.

[24] Goto, M., Han, S.Z., Kim, S.S., Kawagoishi, N. \& Lim, C.Y., Scripta Materialia, 57, pp. 293-296, 2007.

[25] Lynch, S.P., Progression markings, striations, and crack-arrest markings on fracture surfaces, Materials Science and Engineering, A468-470, pp.74-80, 2007. 